\title{
Study of Zwitterionic Homopolymer Polysulfobetaine and Gel Properties in Various Solutions of Different Anion Species and Cation Valences
}

\author{
Afan Hamzah $^{1}$, Daril Ridho Zuchrillah ${ }^{1}$, Eva Oktavia Ningrum ${ }^{1 *}$
}

\begin{abstract}
Zwitterionic homopolymer polysulfobetaine (PBET) gels were synthesized using free radical polymerization. The effect of temperatures on adsorption behavior of the gel and transition temperature of the polymer in various solutions of $\mathrm{LiCl}$, $\mathrm{KCl}, \mathrm{NaCl}, \mathrm{Al}\left(\mathrm{NO}_{3}\right)_{3}, \mathrm{Zn}\left(\mathrm{NO}_{3}\right)_{2}$, and $\mathrm{NaNO}_{3}$ were studied. The tendency of poly(BET)s transition temperature in $\mathrm{Cl}$ solutions very identical. All of poly(BET) solution resulted in Upper Critical Temperature (UCST). Its number increased along with the elevation of salt concentration. The number declined again when the concentration was too high. BET gel successfully adsorbed various ions with the amount of adsorption tendency of $\mathrm{LiCl}<\mathrm{NaCl}<\mathrm{KCl}$.
\end{abstract}

Keywords - Transition temperature, Adsorption, BET

\section{INTRODUCTION}

In recent decades, zwitterionic polymers are known as its utilization on biosensors, catalyst, drug delivery systems, separation materials, etc. This material attracts excellent attention to study due to its specific, sensitive, and instantaneous responsiveness. The first class of polyelectrolytes was synthesized in 1952 [1]. Zwitterionic betaine has both cationic and anionic active groups in a similar polymeric repeat chain with an alkylene group between them. The overall charge of the molecule is neutral. The ion exchange selectivity of zwitterionic betaine can be improved by combining their oppositely charged functional groups in one molecule since it in the same repeating unit chemically bonds with negative and positive charges [2].

Polymer gel is a good system for smart function because of their collapse phase transition. Numerous zwitterionic betaine type gel such as sulfobetaine, carboxybetaine, phosphobetaine, a semi-interpenetrating network and double network have displayed exceptional chemical stability, decent biocompatibility [3], ultralow-fouling, and superb mechanical properties [4].

Recent studies on the characteristic of polysulfobetaine in aqueous solution are mainly focused on its antipolyelectrolyte behavior. In salt solution, ions break intra-chain and intra-group association of the poly(sulfobetaines) due to chain expansion. A series of sulfobetaine component in the copolymeric gels have been developed [5]. These copolymers have behavior to swelling that are associated with their composition and characteristic of external salt solutions. Lee et al. has shown the swelling behavior of hydrogels prepared from copolymerization of 2-

\footnotetext{
${ }^{\mathrm{I}}$ Industrial Chemical Engineering, Faculty of Vocational Studies, Institut Teknologi Sepuluh Nopember, Kampus ITS Sukolilo, Surabaya, 60111. Email: eva-oktavia@chem-eng.its.ac.id
}

hydroxyethyl methacrylate/2-vinyl-1-pyridinium propane sulfonate (HEMA) and zwitterionic monomer N,Ndimethyl(acrylamidopropyl)ammonium propane sulfonate (DMAAPS) in various molar of HEMA and DMAAPS. The copolymeric gels' swelling ratio increases with DMAAPS content; furthermore, the minimum equilibrium swelling ratio is more evident at higher content of DMAAPS in the HEMA/DMAAPS copolymer gels. The salt solution has given a unique effect on the equilibrium swelling degree of this gel. In a salt solution composed of ion having a small charge density, the swelling ratio increases with increasing DMAAPS and salt solution concentrations.

On the contrary, when the salt owns a large charge density, the swelling ratio of the copolymer gel decreases with a rise in salt concentration. The hydrogel was insoluble and its solubilization was linked to the type and added salt concentration. Swelling behavior of sulfobetaine hydrogel prepared from copolymerization of 2-hydroxyethyl methacrylate (HEMA) and a N,N-dimethyl-Nmethacryloxyethyl-N-(3-sulphopropyl)-ammonium betaine (SPE) in salt potassium thiocyanate $(\mathrm{KSCN})$ has been reported [6].

Furthermore, a wide range of thermosensitive polymer have been developed and evaluated for their ability to recover metal ions from aqueous media and most of them are copolymers containing poly( $\mathrm{N}$-isopropyl acrylamide) (polyNIPAAm) and monomers bearing complexing groups. PolyNIPAAm is usually utilized as thermosensitive moiety and the monomers bearing complexing groups give sorption properties. Several papers had been published by Nonaka et al. concerning the usage of thermosensitive copolymer hydrogels with phosphonium groups. These hydrogels had shown a great adsorption capacity for water and good 
antibacterial activities, which depends on the temperature of the solutions [7].

Previous study has been conducted by Naegu et al. on the retention capabilities carboxybetaines (CB) based on the 4vinylpyridine: divinylbenzene macromolecular supports of gel and porous for divalent and trivalent heavy metals. Despite the fact that synthesis has been performed on both zwitterionic ion exchangers in this study and able to retain metal cations and anions from aqueous solution, no retention capacities were reported in alkaline earth metal solutions. In addition, poly(BET) synthesis condition including varied monomer concentration with or without an organic cross-linker has been reported to affect the intrinsic viscosity, polymer yield, gel fraction, and molecular weight [8-9].

Our previous study explored an interesting correlation among the transition activities of poly(BET), swelling behavior of BET gels and adsorption behavior of ion on BET gels. The properties of BET in adsorbing metal ions was found changed on their charge groups in making intra- and/or inter-chain association with the metal ions, which also has a significant effect on the swelling and transition properties. These association was disrupted and dissociated by the addition of salt solution allowing the chain expansion as a result, the swelling degree of the BET gel increased. It was also found that the higher valence of cation of the salt solution the smaller the swelling degree due to the formation of cation bridging between the polymer chains. Furthermore, cross-linker concentration also determined the type of chain association that dominated in the BET network. Considering the sensitive characteristic of BET to the ions, in this work, we have made a detailed study of poly(BET) transition temperature and BET gel adsorption behavior in the presence of various ions. Moreover, different effects in some various ion electron number ( $\mathrm{Li}, \mathrm{Na}, \mathrm{K})$ and valences ( $\mathrm{Na}, \mathrm{Zn}, \mathrm{Al}$ ) on the transition temperature and adsorption behaviour are also elucidated.

\section{METHODS}

\section{A. Materials}

1,3-propanesultone (PS) and acylamido-2-methylpropyl sulfonate (AMPS) were obtained from Tokyo Chemical Industry Co., Ltd. N,N-dimethylamino propylacrylamide (DMAPAA) was obtained from Kohjin Co., Ltd. N,N,N',N'tetramethylethylenediamine (TEMED), N,N'methylenebisacrylamide (MBAA), and ammonium peroxodisulfate (APS) were purchased from Sigma-Aldrich Co. (USA). The solvents employed for the purification of BET was acetonitrile which was obtained from Kanto Chemical Co., Inc. and acetone which was obtained from Nacalai Tesque, Inc.

\section{B.Experimental}

\section{Synthesis of BET}

The BET was produced according to a method described in the previous study [4].

\section{Preparation of Poly $(B E T)$}

In addition to obtain poly(BET), polymerization was done by employing accelerator of TEMED and initiator of APS as delivered in the previous study [4].

Mark-Houwink-Sakurada equation was used to calculate the weight-average molecular weight $[\overline{M w}$ ] which was previously described by Ning et al. [9]. Ubbelohde viscometer was employed, obtaining the intrinsic viscosity $[\eta]$ in $0.1 \mathrm{M} \mathrm{NaCl}$ solution at the temperature of $30^{\circ} \mathrm{C}$. The mean weight of poly (BET) molecular was found to be $1.126 \times 10^{6} \mathrm{~g} / \mathrm{mol}$.

$$
[\eta]=2.3 \times 10^{-5} \overline{M w}^{0.78}
$$

\section{Preparation of BET gel}

BET hydrogels were prepared in the same manner as described in synthesis polymer except using cross-linker of $N, N^{\prime}$-methylenebisacrylamide (MBAA). The preparation condition of BET gels are listed in Table 1.

TABLE 1.

PREPARATION CONDITION OF BET GEL

\begin{tabular}{lll}
\hline & & \multicolumn{1}{c}{$\begin{array}{c}\text { Concentration } \\
{\left[\mathrm{mol}_{\mathbf{m}} \mathbf{m}^{3}\right]}\end{array}$} \\
\hline Monomer & $:$ BET & 1000 \\
Linker & $:$ MBAA & 30 \\
Accelerator & $:$ TEMED & 10 \\
Initiator & $:$ APS & 0.5 \\
\hline \hline Solvent: & water & \\
Temperature: & $50^{\circ} \mathrm{C}$ & \\
Reaction time: & $6 \mathrm{~h}$ &
\end{tabular}

\section{Measurement of poly(BET) UCST}

Poly(BET) UCST was measured using a spectrophotometer equipped with a temperature control system of V-530 from Japan Spectroscopy Co., Ltd. at 600 $\mathrm{nm}$. Since the polymer is soluble in the solution, it was analyzed as transparent above the UCST. Furthermore, when the solution was below the UCST, it became aggregate and insoluble and turning into milky white.

\section{Measurement of ions adsorbed by BET gels}

The adsorption test was done by the following procedures as described of previous study [2, 10]. The following equation was used to determine the cation and anion amount adsorbed in the solution by determining its concentration in the solution before and after the adsorption:

$$
Q=\frac{\left(C_{0}-C\right) V}{m}
$$

Here, $Q$ is the ions adsorbed, $C_{0}$ is the ions concentration in the original solution, $C$ is the ions concentration in the aqueous solution after adsorption, $V$ is the volume target solutions, and $m$ is the mass of dry gels. 


\section{RESULT AND DISCUSSION}

1. Influence on different monovalent cation with common cation $\left(\mathrm{Cl}^{-}\right)$on poly $(\mathrm{BET})$ transition behaviors

The influence of different monovalent cation $(\mathrm{Cl})$ on the poly(BET) transition behavior was examined. The poly(BET) concentration was $20 \mathrm{~g} / \mathrm{l}$. The results shown in Figures 1(a)-(c) indicate that the transition actions of poly(BET) in an aqueous solution of $\mathrm{LiCl}, \mathrm{KCl}, \mathrm{NaCl}$ the UCST increased and then decreased as the salt concentration increased. The tendency and difference between the minimum and maximum value of the UCST are relatively similar. This phenomenon proves that all fixed positive charges $(\mathrm{R} 4 \mathrm{~N}+)$ on BET neutralized by cation are almost the same, leading to a similar effect on the dissociation polymer chains.
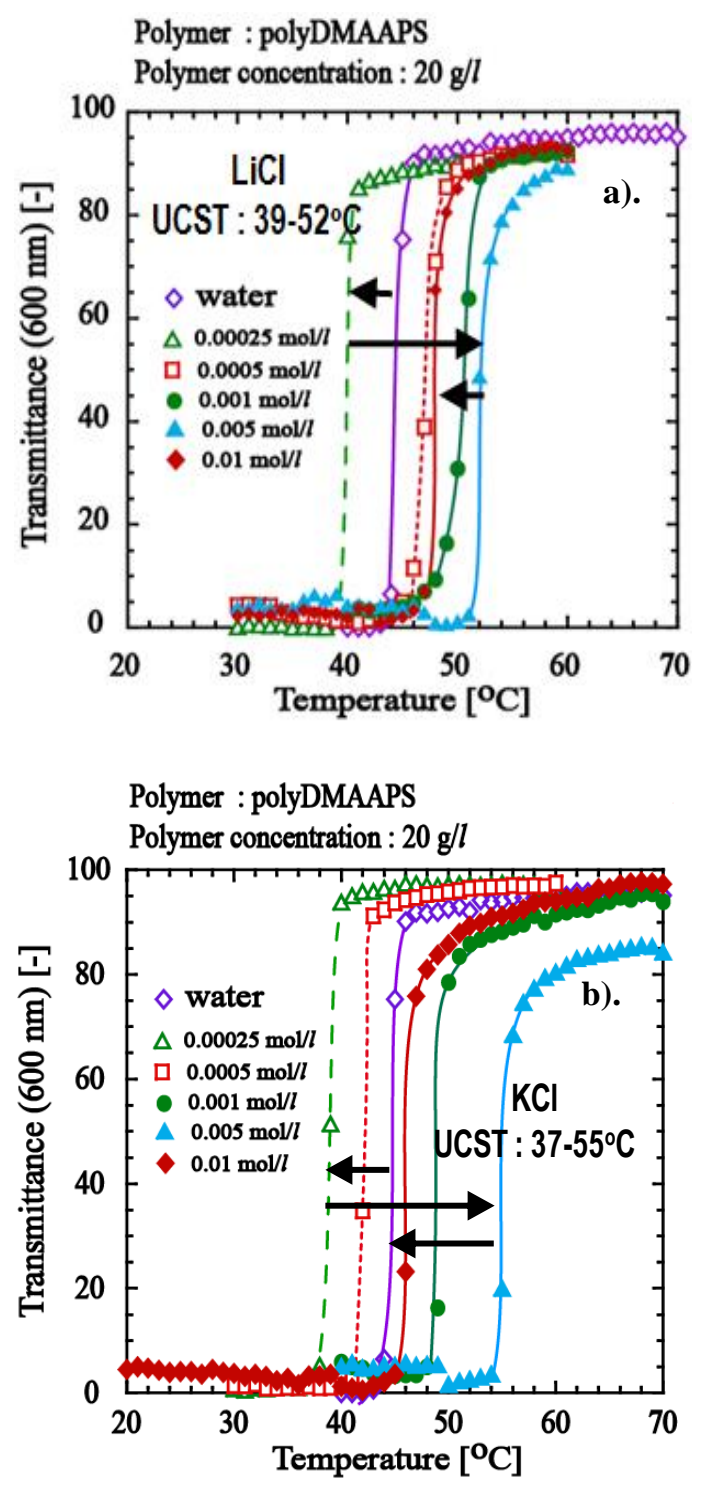

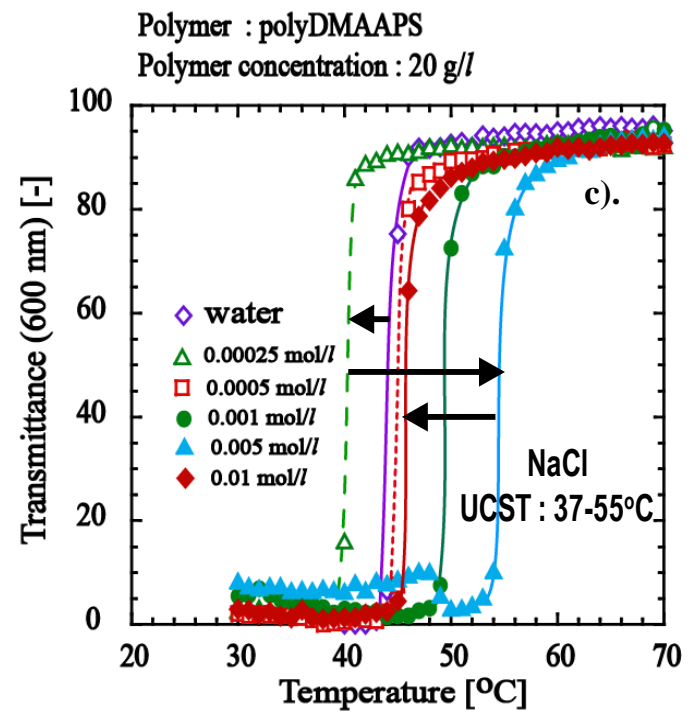

Figure 1. Transition behavior of poly(BET) in various concentration of a). $\mathrm{LiCl}, \mathrm{b}) \mathrm{KCl}, \mathrm{c}) . \mathrm{NaCl}$ solutions with a polymer concentration of $20 \mathrm{~g} / \mathrm{l}$.

\section{Influence on different cation valences with common cation $\left(\mathrm{NO}_{3}^{-}\right)$on poly $(\mathrm{BET})$ transition behaviors}

The thermosensitive behaviors of poly(BET) in salt solutions of $\mathrm{NaNO}_{3}, \mathrm{Zn}\left(\mathrm{NO}_{3}\right)_{2}$, and $\mathrm{Al}\left(\mathrm{NO}_{3}\right)_{3}$ are presented in Figure 2.a-c. When sodium nitrate is added to the poly(BET) solution, the UCST increase first and then decrease as shown in Figure 2.a. As we can see from Figure 2 a. initially, when poly(BET) was dissolved in $\mathrm{NaNO}_{3}$ solution at a low concentration $0.00025 \mathrm{~mol} / l-0.001 \mathrm{~mol} / \mathrm{l}$, the polymer solution was milky white and the UCST was high at around $55^{\circ} \mathrm{C}$ which indicates that the polymer have a more dense network of entanglements. This was considered to be due partial dissociation of ionic pairing/interchain association of the BET chain as a result from the new ionic interaction between the betaine polymer and the ions in the target solution.

Positive and negative charges on the BET gel network, $\mathrm{N}^{+}$ and $\mathrm{SO}_{3}{ }^{-}$, interact with $\mathrm{NO}_{3}^{-}$and $\mathrm{Na}^{+}$in the solution, respectively. The local rupture of zwitterionic groups interchain association promotes more entanglement of the polymer chains which leads to an increase in the polymer coil.

However with the further addition of salt solution concentration to $0.005 \mathrm{~mol} / l$ induced a change in the transparent solution and the UCST decreased from $55^{\circ} \mathrm{C}$ to at around $40^{\circ} \mathrm{C}$. In the case of a high concentration salt solution, the dissociation of ionic pairing is far more effective than in low concentrations due to the amount of ions that can be attributed to interchain bonding rupture is higher. With this great dissociation of ionic pairing the soluble polymer chain dispersed in salt solution was obtained. This behavior is consistent with our previous result. Since the zwitterionic groups interchain associations were destroyed due to new ionic interactions of certain groups with the salt $\mathrm{Na}^{+}$and $\mathrm{Cl}^{-}$ions, the poly(BET) gel adsorption in aqueous $\mathrm{NaCl}$ solution cause the gel dissolution even below the UCST. 
A quite similar phase transition behaviour was also observed when the polymer was dissolved in $\mathrm{Zn}\left(\mathrm{NO}_{3}\right)_{2}$ or $\mathrm{Al}\left(\mathrm{NO}_{3}\right)_{3}$ solution. It is necessary to point out that, although charge groups of the betaine gels interact strongly with the higher valence ions, there was no significant difference in the UCST of the poly(BET) among them. As previously explained, the cation's higher ability, especially divalent and trivalent, to form bridges between sulfonates results in short spacing between the polymer chains. Consequently, the dissociation of the polymer chain is less than or comparable with the chain entanglement. This leads to the more thermal energy required to dissociate unfavourable ionic pairing.
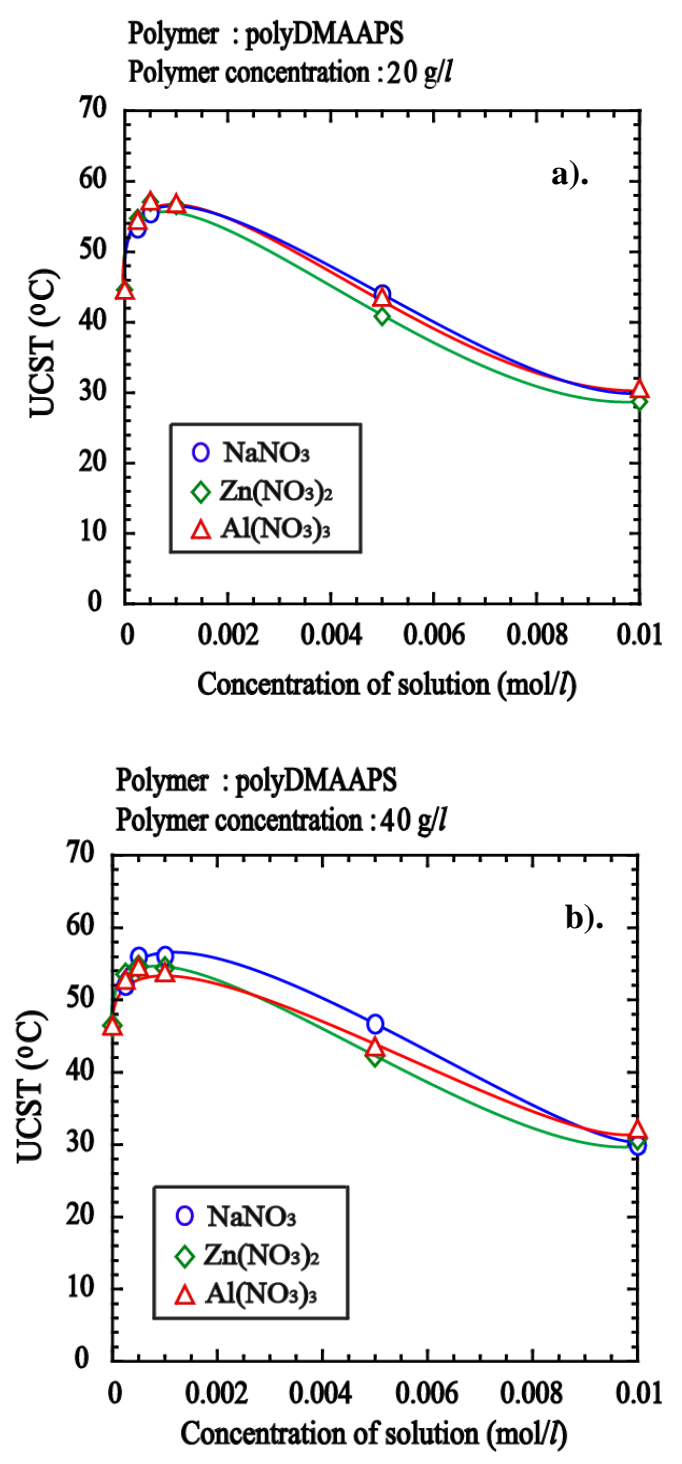

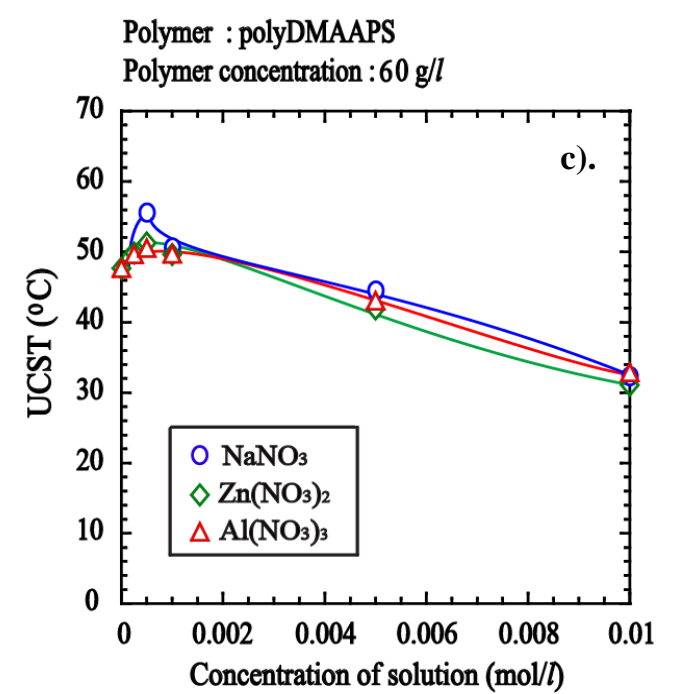

Figure 2. The transition behavior of poly(BET) in nitrate solution of polymer concentration a). $20 \mathrm{~g} / l ; \mathrm{b}) .40 \mathrm{~g} / l ; \mathrm{c}) .60 \mathrm{~g} / \mathrm{l}$

3. Influence on different monovalent cation with common cation $\left(\mathrm{Cl}^{-}\right)$on adsorption amount of poly (BET) gel

The adsorption amounts of the anion $\left(\mathrm{Cl}^{-}\right)$on the BET gel in the solutions composed of the different valence of cations, i.e., $\mathrm{Li}^{+}, \mathrm{K}^{+}$, and $\mathrm{Na}^{+}$, is shown in Figure $3 \mathrm{~b}$ ). It can be seen in Figure 3. that the BET gels demonstrated a higher ability of adsorption to the $\mathrm{K}^{+}$, and $\mathrm{Na}^{+}$compared with that to $\mathrm{Li}^{+}$. The observed order of adsorption was: $\mathrm{LiCl}<\mathrm{NaCl}<\mathrm{KCl}$ solution. This order can be explained due to the hydration force of $\mathrm{Li}^{+}$is more significant than that of $\mathrm{K}^{+}$and $\mathrm{Na}^{+}$.

The adsorption ability of of $\mathrm{K}^{+}$, and $\mathrm{Na}^{+}$compared with $\mathrm{Li}^{+}$ can be explained by Hofmeister series (HS). The Hofmeister Series order for cations is $\mathrm{N}\left(\mathrm{CH}_{3}\right)_{4}{ }^{+}>\mathrm{NH}_{4}{ }^{+}>\mathrm{Cs}^{+}>\mathrm{Rb}^{+}>$ $\mathrm{Na}^{+}>\mathrm{Li}^{+}>\mathrm{Ca}^{2+}>\mathrm{Mg}^{2+}>\mathrm{Zn}^{2+}>\mathrm{Ba}^{2+}$. Cations on the left is less hydrated, thus has the tendency to adsorb more ion than the right side. On the other hand, as $\mathrm{Li}^{+}$ions are strong hydrated species, anions have greater interactions with water molecules than water molecules with each other, thus they are able to break water-water hydrogen bonds, resulting in a lower adsorption potential against ions.

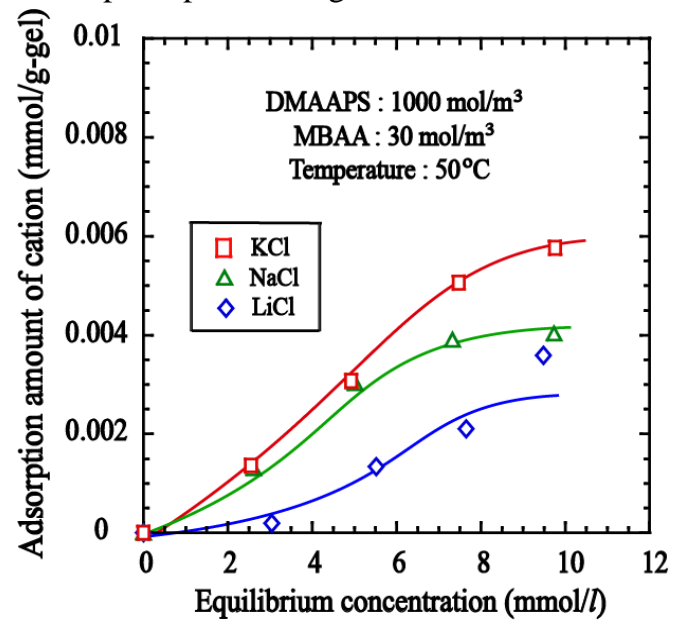

Figure 3. Adsorption amount of difference monolavent cation with common cation $\left(\mathrm{Cl}^{-}\right)$on the BET gel 


\section{CONCLUSION}

The UCST of poly(BET) shows increased first and then decreased with increasing concentration of salt. Transition amount of monovalent cation with common cation $\left(\mathrm{Cl}^{-}\right)$on the BET gel is similar i.e., $\mathrm{LiCl}=\mathrm{NaCl}=\mathrm{KCl}$. Adsorption amount of monovalent cation with common cation $\left(\mathrm{Cl}^{-}\right)$on the BET gel shows a tendency in the order of $\mathrm{LiCl}<\mathrm{NaCl}<$ $\mathrm{KCl}$. In addition, although charge groups of the betaine gels interact strongly with the ions higher valence, there was no significant difference in the UCST of the poly(BET) among them.

\section{REFERENCES}

[1] T. Alfrey and H. Morawetz, "Amphoteric Polyelectrolytes. I. 2Vinylpyridine-Methacrylic Acid Copolymers1,2," J. Am. Chem. Soc., vol. 74, no. 2, pp. 436-438, 1952.

[2] E. O. Ningrum, "CATION- AND ANION-ADSORPTION PROPERTIES OF SULFOBETAINE TYPE GELS AND THEIR RELATIONSHIP WITH SWELLING OR TRANSITION BEHAVIORS IN AQUEOUS SALT SOLUTIONS," Hiroshima University, 2015.

[3] A. Hamzah et al., "Cellulase and xylanase immobilized on chitosan magnetic particles for application in coconut husk hydrolysis," Int. J. Technol., vol. 10, no. 3, 2019, doi: 10.14716/ijtech.v10i3.2905.

[4] E. O. Ningrum, Y. Ohfuka, T. Gotoh, and S. Sakohara, "Effects of specific anions on the relationship between the ion-adsorption properties of sulfobetaine gel and its swelling behavior," Polymer (Guildf)., vol. 59, pp. 144-154, 2015, doi: 10.1016/j.polymer.2015.01.005.

[5] W. F. Lee and P. L. Yeh, "Thermoreversible Hydrogels. IX. Swelling Behaviors of Thermosensitive Hydrogels Copolymerized by N-Isopropylacrylamide with 1-Vinyl-3-(3sulfopropyl) Imidazolium Betaine," J. Appl. Polym. Sci., vol. 77, no. $1, \quad$ pp. 14-23, 2000, doi: 10.1002/(sici)10974628(20000705)77:1<14::aid-app3>3.0.co;2-o.

[6] M. B. Huglin and J. M. Rego, "Influence of a Salt on the Properties of Hydrogels of 2-Hydroxyethyl Methacrylate with a Sulfobetaine Comonomer," Macromolecules, vol. 26, no. 12, pp. 3118-3126, 1993, doi: 10.1021/ma00064a020.

[7] H. Nonaka, A. Kobayashi, and M. Funaoka, "Separation of lignocresol from eucalyptus lignocresol-cellulase complex using organic solvents," Bioresour. Technol., vol. 143, pp. 657-659, 2013, doi: 10.1016/j.biortech.2013.06.060.

[8] V. Neagu, S. Vasiliu, and S. Racovita, "Adsorption studies of some inorganic and organic salts on new zwitterionic ion exchangers with carboxybetaine moieties," Chem. Eng. J., vol. 162, no. 3, pp. 965-973, 2010, doi: 10.1016/j.cej.2010.07.002.

[9] J. Ning, K. Kubota, G. Li, and K. Haraguchi, "Characteristics of zwitterionic sulfobetaine acrylamide polymer and the hydrogels prepared by free-radical polymerization and effects of physical and chemical crosslinks on the UCST," React. Funct. Polym., vol. 73, no. 7, pp. 969-978, 2013, doi: 10.1016/j.reactfunctpolym.2012.11.005.

[10] E. O. Ningrum, A. Purwanto, G. C. Rosita, and A. Bagus, "The properties of thermosensitive zwitterionic sulfobetaine NIPAMco-DMAAPS polymer and the hydrogels: The effects of monomer concentration on the transition temperature and its correlation with the adsorption behavior," Indones. J. Chem., vol. 20, no. 2, pp. 324-335, 2020, doi: 10.22146/ijc.41499. 